\title{
Effect of Modified Swiss Cheese Model on Patient Safety, Patient Safety Culture, and Medication Errors among Nursing Students
}

\author{
Takwa Rashwan Mohamed Abd Elhady ${ }^{1}$, Tarek Mahmoud Shaker ${ }^{2}$, Mohamed Gamal Elsehrawy ${ }^{3}$ \& Walaa \\ Nasreldin Othman ${ }^{4}$ \\ 1. Lecturer Nursing Administration, Faculty of Nursing, Port Said University, Egypt \\ 2. Lecturer of Medical-Surgical Nursing, Faculty of Nursing, Mansoura University, Egypt \\ 3. Lecturer Nursing Administration, Faculty of Nursing, Port Said University, Egypt \\ 4. Assistant Professor of Medical-Surgical Nursing, Faculty of Nursing, Mansoura University, Egypt
}

\begin{abstract}
Background: The Swiss cheese model (SCM) has proven extremely effective and powerful in learning and planning. Aim of the study: evaluate the effect of the Modified Swiss cheese model on patient safety, patient safety culture, and medication errors among nursing students. Methodology: A quasi-experimental research design was used in this study. Setting: The study was conducted at the Faculty of Nursing, Port Said University, Al-Salam \& Al-Nasr hospitals, Port Said. Subjects: Convenient sample, which included all students in the final academic year. Tools: Three tools were used for data collection included Tool I, Patient Safety in Nursing Education Questionnaire. Tool II, Healthcare Professionals Patient Safety Assessment Curriculum Survey. Tool III, The patient safety culture assessment. Results: There is a positive effect of the modified Swiss cheese model on the knowledge, skills, and attitude domains competencies related to patient's safety during post-test compared to the pre-test, with a $p$-value of 0.000. Conclusions: Implementation of modified Swiss cheese model showed positive levels of students' competencies domains (knowledge, skills, and attitude) toward patient safety. Recommendation: A need to revise the nursing curriculum and to use various teaching methods to deliver patient safety education more comprehensively and effectively.
\end{abstract}

\section{Keywords: Education, Modified Swiss cheese Model, Nursing Students \& Safety Competencies.}

\section{Introduction}

Nurses play a critically important role in ensuring patient safety while providing care directly to them, so all members of the nursing team need to understand to be able to develop their knowledge and skills In promoting patient safety (Ranjbar \& Zeydi, 2018).

Patient safety should form a core part of the education of professionals' healthcare (Wu \& Busch, 2019). Patient safety is where the patient does not experience unnecessary suffering or harm during health care delivery (World Health Organization, 2017). According to (Mansour, 2015), nursing schools and health education organizations can provide the required patient safety education. Therefore, patient safety in nursing education is important in all professional environments, and nursing systems (Dillon-Bleich, Burant \& Madigan, 2018).

It is necessary to use clinical reasoning, skilled professional knowledge, and ethics to improve practice, such as cultivating patient safety awareness among nursing students. When students begin their experience in the clinical environment, they understand what clinical safety is, from the students' perspective, a lack of understanding of the clinical conditions that affect the development of safety awareness (Bianchi et al., 2016).

Malpractice nursing care is the main cause of potential harm that may occur in medical institutions. Care misconduct often covers a wide range of conditions and severity, such as administering medication without a prescription, improper nursing care, mishandling of patients (Spath, 2020). Medication administration is an important part of the nurse's role. Nursing Students often lack the knowledge and competency to safely administer medications.

Medication errors in the healthcare environment are considered a serious threat to patients' health (Ibrahim, Ibrahim, Meslamani, \& Mazrouei, 2020). The National Coordinating Council for Medication Error Reporting and Prevention defines a drug error as any preventable event that may cause or lead to improper use of drugs or patient harm during the control of drugs by healthcare professionals, patients, or consumers. Such incidents may be related to professional practices, healthcare products, procedures, and systems (Zirpe et al., 2020). 
The Swiss cheese model is the most widely used accidental analysis model. The Swiss cheese model was developed by Reason in 1990. In this model, the concept of safety layers was used while holes in the safety layers correspond to the deficiencies due to latent errors (e.g. organizational errors, environment, etc). When the holes in the defensive layers align, then the hazard can lead to an accident (Mehmood \& Marco, 2015).

In the modified Swiss cheese model, a classification has been made between the operational errors and errors during the prevention/mitigation actions. Operational errors are related to all those errors that occur during normal operations and consequently can lead the system to an undesired situation, while prevention/mitigation errors are the errors that can happen when the system is already in an undesired situation. The Swiss cheese model has developed into the main paradigm for analyzing human error and patient safety incidents. This model is often cited and generally accepted by patient safety healthcare professionals. They use the model to explain the occurrence of system failures, such as medications errors. (Larouzee \& Le Coze, 2020).

Significant of the study: -

Medication errors in hospitals are still one of the most common causes of accidental injury to patients and the main cause of errors in the healthcare system. It can cause adverse events that threaten the safety of patients and impose a significant economic burden on health services. One-third of the mistakes that hurt patients occur in the nurse's management stageadministering drugs to patients is a very dangerous activity. The nursing is responsible for the drug management stage, including monitoring of effectiveness and adverse reactions. Therefore, professional nurses are likely to expose the error of the drug, because checking the drug before giving it to the patient is one of the main responsibilities.

Aim of the study

Evaluate the effect of the Modified Swiss cheese model on patient safety, patient safety culture, and medication errors among nursing students.

\section{Research hypothesis}

Implementation of a modified Swiss cheese educational program for nursing students will show improvement of patients' safety competencies and decrease medications errors.

\section{Research design:}

A quasi-experimental research design was used in this study.

The study setting

The study was conducted at the faculty of nursing, Port Said University, Al-Salam \& Al-Nasr hospitals, Port-Said governorate.

\section{Subjects}

A convenient sample of 83 students at the final academic year who were agree to participate in the study after excluding the students who participated in the pilot study were included in the study.

Tools of the study

Three tools were used for data collection as follow: -

Tool I: Patient Safety in Nursing Education Questionnaire.

This tool was adapted from (Tella, 2015), to assess the quality of patient safety education for nurses, includes two parts:-

Part A: - Personal characteristics of the students as age, sex, academic score, GPA, etc....

Part B: - Competency domains which involved 57 items classified into 3 competencies domains, knowledge included 10 items, skills domain included 23 items divided into 6 dimensions and attitude domain 24 items divided into 4 dimensions.

Scoring system: -

The scoring system according to (Tella, 2015) included a 5-point Likert scale. The knowledge domain items determine the level of knowledge ranging from $(5=$ very knowledgeable, $1=$ not knowledgeable). The skills domain items measure the level of comfort ranging from $(5=$ very comfortable, $1=$ very uncomfortable) in performing the tasks relevant to patient safety. The attitude domain items measure the level of agreement and range from $(5=$ strongly agree, 1 = strongly disagree) regarding recognitions and behaviors associated with patient safety.

1- Unsatisfactory patient safety competency $(<50 \%)$.

2 - Moderate patient safety competency $(50:<70 \%)$.

3- Satisfactory patient safety competency $(\geq 70 \%)$.

Tool II: - Healthcare Professionals Patient Safety Assessment Curriculum Survey:-

It is a self-administered questionnaire adopted from (Sullivan, 2016) to assess medical students' knowledge about patient safety. It consisted of 8 items asked about errors and near misses.

\section{Tool III: - Patient safety culture assessment,}

Self-administered questionnaire sheet adopted from (Jeong, Liao, Han \& Lee, 2020) to assess the culture of students regarding patient safety, consisting of 14 items. Every response was measured on a five-point Likert scale that ranged from $1=$ strongly disagree to $5=$ fully agree.

Scoring system:

Scoring was divided into three categories,

1 - Negative patient safety culture $(<50 \%)$.

2- Neutral patient safety culture $(50:<70 \%)$.

3- Positive patient safety culture $(\geq 70 \%)$

Ethical consideration

- An official written permission to conduct the study was obtained from the responsible authorities of 
faculty and hospital for data collection after an explanation of the aim of the study.

- Ethical approval was obtained from the faculty research scientific ethic committee.

- Oral consent was obtained from students who accepted to participate voluntarily in this study after illustrating the aim and nature of the study.

- All students' data were considered as a secret with complete confidentiality, the students were informed that they have the right to withdraw any time during the study, and their withdrawal will not affect them.

\section{Data collection}

Data collection was done through 4 phases included preparation assessment, implementation \& evaluation phase.

\section{Preparation phase: -}

This phase started from the beginning of June 2019 until the end of October 2019. This phase involved the review of literature related to the aim of the study. The tools of data collection were translated by the researchers into Arabic form.

\section{Tools validity:}

It was done through a group of jury experts' in the medical-surgical nursing \& nursing administration field to check tools for clarity, relevance, applicability, comprehensiveness, and ease for implementation.

Tool's reliability:

It was done using Cronbach's alpha test, the tool I was 0.85 , which refers to an acceptable reliability level, while tool II was 0.89 , finally, tool III was 0.90 . Pilot study: -

A pilot study was conducted before starting the study on $10 \%$ of the total subjects. They were randomly selected and excluded from the total population. Necessary modifications were done.

Assessment phase: -

After the finalization of data collection tools, the tools were distributed to the students in their study place in the presence of the researchers for any clarification to gather baseline data concerning students' knowledge, skills, and attitude toward patient safety using the tool I. Students' opinion about healthcare professionals patient safety assessment curriculum survey was examined using tool II. Also, a patient safety culture assessment was administrated pre and posts the program to collect data related to students' opinions about patient safety culture assessment using tool III.

Implementation phase: -

Based on the data collected during the assessment phase, the researchers appliea the Modified Swiss Cheese Model to meet students' needs which included how to use the model, definition of a medications error, \& hazards of a medications error, and patient safety.
The Modified Swiss Cheese Model was implemented during the period from February 2020 till March 2020 in the Faculty of Nursing - Port-Said University. The Modified Swiss Cheese Model was implemented twice for students based on the available time. The total time allocated to each group to complete the entire procedure is 6 hours. There are six classes in three weeks, and each class is one hour long. The program period starts from 11 am to $12: 00 \mathrm{pm}$ at the Faculty of Nursing, Port-Said University. Different teaching strategies (Lecture, group discussion, and brainstorming) were used. At the beginning of each session, the researcher summarized the previous sessions, apply adult learning principles by setting aside time for questions and discussions.

Evaluation phase: -

This phase started from January 2020 to March 2020. During this phase, the researchers used the same tools ( I, II, and III) to evaluate the effect of the Modified Swiss Cheese Model immediately after implementation of the program through a comparison of post-test results with the baseline findings obtained in the pre-test assessment. This part was done at the Al-Salam \& Al-Nasr hospitals, Port Said governorate. Statistical analysis.

The collected data were organized, tabulated, and statistically analyzed using SPSS software (Statistical Package for the Social Sciences, version 21, SPSS Inc. Chicago, IL, USA). For qualitative data, use the chi-square test was utilized to compare two and more groups. Use Pearson's correlation coefficient (r) to assess the correlation between variables. Use significance at $\mathrm{p}$-value $(<0.05$ to explain the results of the significance test. 


\section{Results}

Table (1): Distribution of student's according to demographic characteristics

\begin{tabular}{|c|c|c|}
\hline Socio demographic characteristics & No $=83$ & $\%$ \\
\hline \multicolumn{3}{|l|}{ Age (years) } \\
\hline 21 years & 30 & 36.1 \\
\hline 22years & 37 & 44.6 \\
\hline 23 years & 16 & 19.3 \\
\hline \multicolumn{3}{|l|}{ Gender } \\
\hline Male & 33 & 39.8 \\
\hline Female & 50 & 60.2 \\
\hline \multicolumn{3}{|l|}{ GPA score } \\
\hline Less than 2 & 7 & 8.4 \\
\hline $2:>3$ & 31 & 37.3 \\
\hline $3: 3.5$ & 36 & 43.5 \\
\hline More than 3.5 & 9 & 10.8 \\
\hline \multicolumn{3}{|l|}{ Previous training regarding patient safety } \\
\hline No & 76 & 91.6 \\
\hline Yes & 7 & 8.4 \\
\hline \multicolumn{3}{|l|}{ Private hospital working. } \\
\hline No & 41 & 49.4 \\
\hline Yes & 42 & 50.6 \\
\hline \multicolumn{3}{|l|}{ Years of experience } \\
\hline Not work & 41 & 49.4 \\
\hline Less than one year & 17 & 20.5 \\
\hline $1-3$ years & 18 & 21.7 \\
\hline More than three years & 7 & 8.4 \\
\hline \multicolumn{3}{|l|}{ Department } \\
\hline Not work & 41 & 49.4 \\
\hline Medical & 4 & 4.8 \\
\hline Surgical & 4 & 4.8 \\
\hline Operation room & 2 & 2.4 \\
\hline Emergency department & 5 & 6.0 \\
\hline Obstetrics and gynecology & 2 & 2.4 \\
\hline ICU & 14 & 16.9 \\
\hline NICU & 11 & 13.3 \\
\hline \multicolumn{3}{|l|}{ Previous attending patient safety lecture } \\
\hline No & 61 & 73.5 \\
\hline Yes & 22 & 26.5 \\
\hline
\end{tabular}

Table (2): Student's skills competencies score related to Patient Safety (N=83).

\begin{tabular}{|c|c|c|c|c|c|c|}
\hline \multirow{2}{*}{ Dimensions } & \multicolumn{2}{|c|}{ Pre } & \multicolumn{2}{|c|}{ Post } & \multirow{2}{*}{$\mathrm{X}^{2}$} & \multirow{2}{*}{$\mathbf{p}$} \\
\hline & No & $\%$ & No & $\%$ & & \\
\hline \multicolumn{7}{|l|}{ Error response \& reporting } \\
\hline Unsatisfactory & 46 & 55.4 & 10 & 12.0 & \multirow{3}{*}{6.674} & \multirow{3}{*}{$0.001 *$} \\
\hline Moderate & 34 & 41.0 & 27 & 32.5 & & \\
\hline Satisfactory & 3 & 3.6 & 46 & 55.4 & & \\
\hline \multicolumn{7}{|l|}{ Error communication } \\
\hline Unsatisfactory & 45 & 54.2 & 5 & 6.0 & \multirow{3}{*}{7.176} & \multirow{3}{*}{$0.001 *$} \\
\hline Moderate & 35 & 42.2 & 18 & 21.7 & & \\
\hline Satisfactory & 3 & 3.6 & 60 & 72.3 & & \\
\hline \multicolumn{7}{|c|}{ Resources utilization/evidence-based practice } \\
\hline Unsatisfactory & 44 & 53.0 & 7 & 8.4 & \multirow{3}{*}{6.450} & \multirow{3}{*}{$0.001 *$} \\
\hline Moderate & 36 & 43.4 & 38 & 45.8 & & \\
\hline Satisfactory & 3 & 3.6 & 38 & 45.8 & & \\
\hline \multicolumn{7}{|l|}{ Safe nursing practice } \\
\hline Unsatisfactory & 49 & 59.0 & 4 & 4.8 & \multirow{3}{*}{6.427} & \multirow{3}{*}{$0.001 *$} \\
\hline Moderate & 26 & 31.3 & 37 & 44.6 & & \\
\hline Satisfactory & 8 & 9.7 & 42 & 50.6 & & \\
\hline
\end{tabular}




\begin{tabular}{|c|c|c|c|c|c|c|}
\hline \multirow{2}{*}{ Dimensions } & \multicolumn{2}{|c|}{ Pre } & \multicolumn{2}{|c|}{ Post } & \multirow{2}{*}{$\mathbf{X}^{2}$} & \multirow{2}{*}{$\mathbf{p}$} \\
\hline & No & $\%$ & No & $\%$ & & \\
\hline \multicolumn{7}{|l|}{ Infection prevention } \\
\hline Unsatisfactory & 45 & 54.2 & 10 & 12.0 & \multirow{3}{*}{6.532} & \multirow{3}{*}{$0.001^{*}$} \\
\hline Moderate & 35 & 42.2 & 20 & 24.1 & & \\
\hline Satisfactory & 3 & 3.6 & 53 & 63.9 & & \\
\hline \multicolumn{7}{|c|}{ Precise communications during hand offs } \\
\hline Unsatisfactory & 35 & 42.2 & 12 & 14.5 & \multirow{3}{*}{5.331} & \multirow{3}{*}{$0.001 *$} \\
\hline Moderate & 41 & 49.4 & 27 & 32.5 & & \\
\hline Satisfactory & 7 & 8.4 & 44 & 53.0 & & \\
\hline
\end{tabular}

Table (3): Student's attitude scores related to Patient Safety (N=83).

\begin{tabular}{|c|c|c|c|c|c|c|}
\hline \multirow{2}{*}{ Dimensions } & \multicolumn{2}{|c|}{ Pre } & \multicolumn{2}{|c|}{ Post } & \multirow{2}{*}{$\mathbf{X}^{2}$} & \multirow{2}{*}{$\mathbf{p}$} \\
\hline & No & $\%$ & No & $\%$ & & \\
\hline \multicolumn{7}{|c|}{ Patient safety promotion/prevention strategy } \\
\hline Unsatisfactory & 64 & 77.1 & 1 & 1.2 & \multirow{3}{*}{7.766} & \multirow{3}{*}{$0.000^{*}$} \\
\hline Moderate & 19 & 22.9 & 32 & 38.6 & & \\
\hline Satisfactory & 0 & 0 & 50 & 60.2 & & \\
\hline \multicolumn{7}{|c|}{ Health care professionals responsibility } \\
\hline Unsatisfactory & 71 & 85.5 & 3 & 3.6 & \multirow{3}{*}{7.710} & \multirow{3}{*}{$0.000^{*}$} \\
\hline Moderate & 12 & 14.5 & 39 & 47.0 & & \\
\hline Satisfactory & $\overline{0}$ & 0 & 41 & 49.4 & & \\
\hline \multicolumn{7}{|c|}{ Error reporting and disclosing } \\
\hline Unsatisfactory & 41 & 49.4 & 5 & 6.0 & \multirow{3}{*}{6.991} & \multirow{3}{*}{$0.000 *$} \\
\hline Moderate & 42 & 50.6 & 43 & 51.8 & & \\
\hline Satisfactory & 0 & 0 & 35 & 42.2 & & \\
\hline \multicolumn{7}{|c|}{ Patient safety culture components } \\
\hline Unsatisfactory & 54 & 65.1 & 2 & 2.4 & \multirow{3}{*}{7.710} & \multirow{3}{*}{$0.000 *$} \\
\hline Moderate & 29 & 34.9 & 23 & 27.7 & & \\
\hline Satisfactory & 0 & 0 & 58 & 69.9 & & \\
\hline
\end{tabular}

Table (4): Student total scores levels of competencies domains toward patient safety $(N=83)$

\begin{tabular}{|c|c|c|c|c|c|c|}
\hline \multirow{2}{*}{ Dimensions } & \multicolumn{2}{|c|}{ Pre } & \multicolumn{2}{|c|}{ Post } & \multirow{2}{*}{$\mathbf{X}^{2}$} & \multirow[b]{2}{*}{$\mathbf{p}$} \\
\hline & No & $\%$ & No & $\%$ & & \\
\hline \multicolumn{7}{|l|}{ Knowledge } \\
\hline Unsatisfactory & 64 & 77.1 & 11 & 13.3 & \multirow{3}{*}{7.089} & \multirow{3}{*}{$0.000 *$} \\
\hline Moderate & 19 & 22.9 & 33 & 39.8 & & \\
\hline Satisfactory & 0 & 0 & 39 & 47.0 & & \\
\hline \multicolumn{7}{|l|}{ Skills } \\
\hline Unsatisfactory & 56 & 67.5 & 3 & 3.6 & \multirow{3}{*}{7.766} & \multirow{3}{*}{$0.000 *$} \\
\hline Moderate & 27 & 32.5 & 28 & 33.7 & & \\
\hline Satisfactory & 0 & 0 & 52 & 62.7 & & \\
\hline \multicolumn{7}{|l|}{ Attitude } \\
\hline Negative & 77 & 92.8 & 0 & 0 & \multirow{3}{*}{8.146} & \multirow{3}{*}{$0.000 *$} \\
\hline Neutral & 6 & 7.2 & 26 & 31.3 & & \\
\hline Positive & 0 & 0 & 57 & 68.7 & & \\
\hline \multicolumn{7}{|l|}{ Culture } \\
\hline Negative & 55 & 66.3 & 2 & 2.4 & \multirow{3}{*}{6.617} & \multirow{3}{*}{$0.000 *$} \\
\hline Neutral & 25 & 30.1 & 62 & 74.7 & & \\
\hline Positive & 3 & 3.6 & 19 & 22.9 & & \\
\hline \multicolumn{7}{|l|}{ Total } \\
\hline Unsatisfactory & 75 & 90.4 & 0 & 0 & \multirow{3}{*}{8.119} & \multirow{3}{*}{$0.000 *$} \\
\hline Moderate & 8 & 9.6 & 34 & 41.0 & & \\
\hline Satisfactory & 0 & 0 & 49 & 59.0 & & \\
\hline
\end{tabular}


Table (5): Correlation between students competencies domains toward patient safety after implementation of Modified Swiss Cheese Model.

\begin{tabular}{|c|c|}
\hline Domains & Knowledge \\
\hline \multirow{2}{*}{ Skills } & $\mathrm{r}=0.134$ \\
& $\mathrm{p}=0.228$ \\
\hline \multirow{2}{*}{ Attitude } & $\mathrm{r}=0.335$ \\
& $\mathrm{p}=0.011^{*}$ \\
\hline \multirow{2}{*}{ Culture } & $\mathrm{r}=0.250$ \\
& $\mathrm{p}=0.023^{*}$ \\
\hline
\end{tabular}

Table (1): Shows that $60 \%$ of the students were female; two-fifths of the students have GPA scores from 3:3.5. The majority didn't participate in previous training related to patient safety, and half of the students were working in the intensive care unit. Finally, $73.5 \%$ of students didn't attend any lecture about patient safety at the faculty.

Table (2): Shows that there is a significant improvement of all competency skills domain during the post-test compared to pre-test, $p$-value $=0.001^{*}$.

Table (3): Shows that there is a highly significant improvement of all competency attitude domain during the post-test compared to the pre-test, $p$-value $=0.001 * *$

Table (4): Shows that there is a highly significant improvement regarding knowledge, skills, attitude, and culture competencies domain during post-test compared to the pre-test. Also, there is a highly significant improvement of the total score level of all competencies domains during post-test compared to pre-test, $p$-value $=0.000^{*}$.

Table (5): This shows that, a mild positive significant correlation between knowledge \& attitude competency domains. Also the mild positive significant correlation between knowledge competency with culture competency at the postprogram phase.

\section{Discussion}

Patient safety concerns have emerged on a global level due to the increasing number of injuries and fatalities in healthcare (Baines, Langelaan, de Bruijne \& Wagner, 2015). In undergraduate nursing education, patient safety capabilities include three areas knowledge, skills, and attitudes, aiming to help nursing students to be prepared well for a medical environment that requires a high level of quality and safety performance (Altmiller \& Hopkins-Pepe, 2019). Therefore, this study was carried out to evaluate the effect of the modified Swiss cheese model on patient safety, patient safety culture, and medication errors among nursing students.

Discussion of the results had presented in the following sequences:
1. Demographic characteristics of the studied group.

2. Assessment of students' competencies domains score (knowledge, skills, attitude, and culture) related to patient safety.

3. Relation between total score level of students' competencies domains (Knowledge, skills, culture, and attitude) toward patient safety and their characteristics after implementation of the program.

4. Correlation between students' competencies domains toward patient safety after implementation of the program.

\section{Demographic characteristics:}

The findings of the study revealed that most of the students had ages ranging between 21 to 22 years; this was in agreement with (Cha et al., 2020) who reported that $75.6 \%$ of students were between 20 and 29 years. The result comes in contrast with (Hannele, Susanna, \& Maliheh, 2018) who noted that the mean age of students was 30 years. Our study results showed that more than half of the studied group $(60 \%)$ was female, this finding in the line with (Julianto, Thiangchanya, \& Boonyoung, 2014) who reported that two-thirds of the students were female. Also, (Hannele, Susanna, \& Maliheh, 2017) noted that the majority of participants $92 \%$ were women. These findings disagreed with (Olaf, Vos Mieke \& Eric, 2017) who reported that $82.2 \%$ of the participant were male.

Concerning work years of experience and workplace, the study revealed that nearly half of the studied group did not work and less than a quarter of them have less than one year of experience at work. It also noted that only $16.9 \%$ of nursing students work at the Critical Care Unit (CCU). This comes in line with (Jeon et al., 2020) who noted that $44 \%$ of students did not have any job. The same author's study contrasted with our result in which they reported 33\% of students worked in a public hospital, $35.6 \%$ reported 1-2 years of experience and $31.1 \%$ reported less than 1 year of experience.

On the other hand, the findings come in disagree with (Hannele, Susanna, \& Maliheh, 2017) who noted that almost all pre-registered nursing graduates who participated in the study reported some health care 
work experience (97.4), and approximately $41 \%$ of graduate participants had less than one year of health care workers. Also, in contrast (Langari et al., 2017) mentioned that the majority of the student had some work experience in health care.

The study showed that $73.5 \%$ of students were not attending any lecture about patient safety at the faculty. This comes in to agree with a previous research study by (Steven et al., 2014; Tella et al., 2014) who mentioned that nursing students did not take patient safety as a clear topic through the educational process. The study also agrees with (Hannele, Susanna, \& Maliheh, 2017) who reported that the majority of nursing students in the UK and Finland (69\%) did not find a separate patient safety module in their nursing curriculum.

The negative practice of students including patient safety in their curricula is worrying, the review shows that both the faculty and staff of the nursing program nursing educators believe that the curriculum involves core competencies for patient safety; the passive approach of students to include patient safety in the curriculum is worrying. Therefore, early research is crucial to reveal the different views of the content of patient safety and satisfaction between teachers and students (Mansour, Al Shadafan, Abu-Sneineh \& AlAmer, 2018).

Concerning the ssessment of students' competencies domains score (knowledge, skills, attitude, \& culture) related to patient safety. The findings of the study revealed that the levels of students' skill Competency scores toward patient safety were unsatisfactory in the pre-program stage, while showed statistically significant improvement of students in all items of skills competency toward patient safety immediately post-program. Students' pre-program unsatisfactory scores may be secondary to one of the following causes: they didn't have enough training about Patient Safety skills or were careless and had a low interest to enhance their skills.

The highest improvements of students' skill competency toward patient safety were related to communication-related errors. This enhancement may be a return to simple, clear, and concise presentation and application methods and the availability of related media, providing more explanations for understanding text and frequent repetition and encouraging them to share in the program. In addition, students showed interest in the content of the course revealed by the active interaction during the course. They also need how to communicate the error, observations, or concerns related to hazards that affect the patients.

These results are supported by the findings of a study done by (Sullivan, 2016) that applied for nursing students. This study aimed to explore students' perceptions of their knowledge, experience, and attitudes related to error management in the clinical unit. An educational intervention was provided on the Just Culture model and its application to the handling of student errors. Their results revealed that the student does not achieve a satisfactory rating during the clinical experience before the educational program. This result is disagreed with (Elsehrawy, Gaber \& Adam, 2015) who stated that teamwork within hospital units dimension was the highest response in medical units and surgical units, also Feedback and communication error was the lowest response in medical units and was the lowest response in surgical units.

Concerning attitude, the current study showed that the majority of the students had a negative attitude during the pretest, which turned into neutral and positive during the posttest. This finding was in the line with (Aly, 2019) who mentioned A highly positive attitude towards patient safety indicates that their attitude is not affected by academic level or learning experience. On the contrary, (Njeri, 2017) described the student attitude as positive during the study. Also, (Nadarajan, Karuthan, Rajasingam, \& Chinna, 2020) mentioned that a large majority of students reported attitudes supportive of patient safety on most measures.

Cultivating students' clinical nursing ability is the main goal of undergraduate nursing education. However, traditional learning strategies to achieve this goal have not been successful. The current study showed that the majority of the students had an unsatisfactory level of competencies domains (knowledge, attitude, skills, and culture) toward patient safety during pretest, which improved during post-test. This finding was in the line with (Hagqvist, et al., 2020) who mentioned that the student had an excellent competency level after the intervention. Also, (Ibrahim, Abdelaziz, \& Akel, 2019) mentioned that nursing student competency was higher during the posttest. On contrary (Jo \& Gu, 2021) reported that there was no significant difference regarding competencies between pre and post-test.

Relation between total score level of students' competencies domains (Knowledge, skills, culture, and attitude) toward patient safety and their characteristics after implementation of the program.

The study showed that there were no statistically significant differences between students' competencies domains toward patient safety and their characteristics at post-program intervention. This is in accordance with (Nabilou, Feizi \& Seyedin, 2015) who noted that there were no significant relationships between students' perception of patient safety and 
their field of study, gender, and year of entry to the university.

Correlation between students' competencies domains toward patient safety after implementation of the program.

The findings of the study showed that, significant positive correlation between knowledge competency with Attitude competency toward patient safety at the post-program phase. Also, a significant positive correlation between knowledge competency with culture competency toward patient safety at the postprogram phase. This comes in line with (Solomon, Bell, Jaekel \& Wright, 2014) who stated that there are important reasons to study the impact of safety culture on students' safety perception. A culture of justice allows organizations to achieve a culture of safety by clearly defining expectations and shared responsibilities. Maintaining the anonymity, voluntary nature, and security of the project is critical to ensuring integrity, meeting the ethical requirements of research, and gaining the trust of employees. The current study also revealed that there was no significant correlation between student knowledge and skills competencies toward patient safety. This finding was agreed by (Zazzi, 2020) who mentioned that not particularly statistically significant. In contrast, (Parson, Childs \& Elzie, 2018) mentioned that there was a significant correlation between knowledge and skills competencies.

Finally, the assessment of students' patient safety abilities is an important part of improving patient safety education because it highlights the parts of the curriculum that students feel need to be developed. Therefore, it should be noted that patient safety education still needs to be carried out through a variety of teaching methods and curriculum revisions.

\section{Conclusions:}

Implementation of educational program regarding modified Swiss cheese model showed positive levels of students' competencies domains (knowledge, skills, and attitude) toward patient safety.

\section{Recommendation:}

- The need to revise the nursing curriculum and to use various teaching methods to deliver patient safety education more comprehensively and effectively.

- Further research to explore the views of nursing students and faculty on the content and needs of patient safety in nursing courses, and apply to a large sample size.

\section{References}

- Altmiller, G. \& Hopkins-Pepe, L., (2019): Why Quality and Safety Education for Nurses (QSEN)
Matters in Practice. The Journal of Continuing Education in Nursing, 50(5), pp.199-200.

- Aly, E. (2019): Patient Safety 2019: Saudi nursing student's attitudes towards patient safety and the influencing factors: Aquantitative \& qualitative study at the college of nursing-JeddahEbtsamAlyAbou Hashish, King Saud binAbdulAziz University for Health Sciences.

- Baines, R., Langelaan, M., de Bruijne, M. \& Wagner, C., (2015): Is researching adverse events in hospital deaths a good way to describe patient safety in hospitals: a retrospective patient record review study. BMJ Open, 5(7), p.e007380.

- Bianchi, M., Bressan, V., Cadorin, L., Pagnucci, N., Tolotti, A., Valcarenghi, D., Watson, R., Bagnasco, A. \& Sasso, L., (2016): Patient safety competencies in undergraduate nursing students: a rapid evidence assessment. Journal of Advanced Nursing, 72(12), pp.2966-2979.

- Cha, C., Hwang, H., An, B., Jeong, S. \& Yang, S., (2020): Nursing student and faculty competency improvement through a nurse-bridging program in Cambodia. Nurse Education Today, 93, p.104523.

- Dillon-Bleich, K.., Burant, C. \& Madigan, E., (2018): Keeping Patients Safe: The Relationships Among Structural Empowerment, Systems Thinking, Level of Education, Certification And Safety Competency. Phd. Frances Payne Bolton School of Nursing Case Western Reserve University.

- Elsehrawy, M., Gaber, H. \& Adam, S., (2015): Nurse's Awareness Regarding Patient Safety Culture at Mansoura University Hospital. Mansoura Nursing Journal, 2(1), pp.137-146.

- Grocott, K., (2014): Patient Safety and Managing Risk in Nursing Fisher Melanie and Scott Margaret Patient Safety and Managing Risk in Nursing200pp $£ 18.99$ SAGE/Learning Matters 9781446266885 1446266885. Nursing Management, 21(2), pp.1414.

- Hagqvist, P., Oikarainen, A., Tuomikoski, A., Juntunen, J. \& Mikkonen, K., (2020): Clinical mentors' experiences of their intercultural communication competence in mentoring culturally and linguistically diverse nursing students: A qualitative study. Nurse Education Today, 87, p.104348.

- Hannele T., Susanna T., \& Maliheh N., (2017): Self-Assessment of Patient Safety Competence: A Questionnaire Survey ofFinal Year British and Finnish Pre-Registration Nursing Students. International Journal of Caring Sciences, September-December 2017, 10(3) Page 1212.

- Ibrahim, A., Abdelaziz, T. \& Akel, D., (2019): The relationship between undergraduate nursing students' satisfaction about clinical learning 
environment and their competency selfefficacy. Journal of Nursing Education and Practice, 9(11), p.92.

- Jang, H. \& Lee, N., (2017): Patient safety competency and educational needs of nursing educators in South Korea. PLOS ONE, 12(9), p.e0183536.

- Jeon, Y., Ritmala-Castrén, M., Meretoja, R., Vahlberg, T. \& Leino-Kilpi, H., (2020): Anaesthesia nursing competence: Self-assessment of nursing students. Nurse Education Today, 94, p. 104575 .

- Jeong, H., Liao, H., Han, S. \& Lee, W., (2020): An Application of Item Response Theory to Scoring Patient Safety Culture Survey Data. International Journal of Environmental Research and Public Health, 17(3), p.854.

- Jo, M. \&Gu, M., (2021): Development and effects of a nursing information literacy competency education program for undergraduate nursing students. The Journal of Korean Academic Society of Nursing Education, 27(2), pp.210-222.

- Julianto, R., Thiangchanya, P., \& Boonyoung, N. (2014): Nurses' Patient Safety Competencies in Aceh Province, Indonesia. Nurse Media Journal of Nursing, 4, 659-670.

- Langari, M., Tella, S., Smith, N., \& Turunen, H., (2017): Self-Assessment of Patient Safety Competence: A Questionnaire Survey of Final Year British and Finnish Pre-Registration Nursing Students. International Journal of Caring Sciences.10 (3), P., 1212.

- Larouzee, J. \& Le Coze, J., (2020): Good and bad reasons: The Swiss cheese model and its critics. Safety Science, 126, p.104660.

- Mansour, M., 2015. Factor analysis of nursing students' perception of patient safety education. Nurse Education Today, 35(1), pp.32-37.

- Mansour, M., Al Shadafan, S., Abu-Sneineh, F. \& AlAmer, M., (2018): Integrating Patient Safety Education in the Undergraduate Nursing Curriculum: A Discussion Paper. The Open Nursing Journal, 12(1), pp.125-132.

- Mehmood A, \& Marco P. (2015): Modified Swiss Cheese Model to Analyse the Accidents. The Italian Association of Chemical Engineering VOL. 43, 2015 DOI: 10.3303/CET1543207 Online at www.aidic.it/cet.

- Mohamed, O., Ibrahim, R., Al Meslamani, A. \& Al Mazrouei, N., (2020): Dispensing errors in community pharmacies in the United Arab Emirates: investigating incidence, types, severity, and causes. Pharmacy Practice, 18(4), p.2111.

- Nabilou, B., Feizi, A. \& Seyedin, H., (2015): Patient Safety in Medical Education: Students'
Perceptions, Knowledge and Attitudes. PLOS ONE, 10(8), p.e0135610.

- Nadarajan, S., Karuthan, S., Rajasingam, J. \& Chinna, K., (2020): Attitudes Toward Patient Safety among Medical Students in Malaysia. International Journal of Environmental Research and Public Health, 17(21), p.7721.

- Njeri, C., (2017): Determinants of Satisfaction with Training Process among Final Year Nursing Students at Kenya Medical Training College. Nursing \& Healthcare International Journal, 1(4).

- Olaf, T., Vos Mieke, D. \& Eric, F., (2017): The Effectiveness of a Course on Patient Safety Management on the Patient Safety Competencies by Final Year Bachelor of Nursing Students in the Netherlands. Health Education and Care, 2(4).

- Parson, L., Childs, B. \& Elzie, P., (2018): Using Competency-Based Curriculum Design to Create a Health Professions Education Certificate Program the Meets the Needs of Students, Administrators, Faculty, and Patients. Health Professions Education, 4(3), pp.207-217.

- Ranjbar, H. \& Zeydi, A., (2018): Patient Safety: An Important yet Neglected Issue in Nursing Education. Journal of Patient Safety, 14(3), pp.e35e35.

- Safarpour, H., Tofighi, M., Malekyan, L., Bazyar, J., Varasteh, S. \& Anvary, R., (2017): Patient Safety Attitudes, Skills, Knowledge and Barriers Related to Reporting Medical Errors by Nursing Students. International Journal of Clinical Medicine, 08(01), pp.1-11.

- Solomon, A., Bell, S., Jaekel, C. \& Wright, T., (2014): Enhancing Nurses' Perceptions of Patient Safety Culture Through the Just Culture Model. $\mathrm{PhD}$. Health Services Faculty, Walden University.

- Spath, P., (2020): Error Reduction in Health Care: A Systems Approach to Improving Patient, Chapter 13 How Information Technology Can Improve Patient Safety,p, 269. Saf. John Wiley \& Sons.

- Steven, A., Magnusson, C., Smith, P. \& Pearson, P.H. (2014): Patient safety in nursing education:contexts, tensions and feeling safe to learn. Nurse Education Today 34: 277-284.

- Sullivan, M., (2016): Nursing Faculty Perception of the Just Culture Model and its Application to the Response and Reporting of Student Errors and Near Misses. PhD thesis. Faculty of the Doctor of Nursing Practice Program of Carlow University.

- Tella, S. (2015): Learning about patient safety in preregistration nursing education. Comparing Finnish and British Nursing student's evaluations, University of Eastern Finland. Available at: http://epublications.uef.fi/pub/urn_isbn_978-95261-1892-5/urn isbn 978-952-61-1892-5.pdf. 
- World Health Organization. (2017): Patient safety: making health care safer. World Health Organization. Retrieved https://apps.who.int/iris/handle/10665/255507.

- Wu, A., \& Busch, I. (2019): Patient safety: a new basic science for professional education. GMS journal for medical education, 36(2), Doc21. https://doi.org/10.3205/zma001229.

- Zazzi, E., (2020): Contributors to the development of intercultural competence in nursing students. Nurse Education Today, 90, p.104424.

- Zirpe, K., Seta, B., Gholap, S., Aurangabadi, K., Deshmukh, A., Wankhede, P., Suryawanshi, P., Vasanth, S., Kurian, M., Philip, E., Jagtap, N. \& Pandit, E., (2020): Incidence of Medication Error in Critical Care Unit of a Tertiary Care Hospital: Where Do We Stand?. Indian Journal of Critical Care Medicine, 24(9), pp.799-803. 